\title{
Atuação da Delegacia de Proteção à Criança e ao Adolescente em Casos de
}

\section{Violência Sexual}

\author{
Fernanda Corrêa* \\ Faculdade Meridional de Passo Fundo - IMED, Passo Fundo, RS, Brasil \\ ORCID: https://orcid.org/0000-0001-8975-8595 \\ Jean Von Hohendorff** \\ Faculdade Meridional de Passo Fundo - IMED, Passo Fundo, RS, Brasil \\ ORCID: http://orcid.org/0000-0002-7414-5312
}

\begin{abstract}
RESUMO
A violência sexual contra crianças e adolescentes é um grave problema no Brasil. Estratégias precisam ser planejadas visando sua prevenção e o cuidado das vítimas. O presente estudo objetivou compreender as ações de uma delegacia de proteção à criança e ao adolescente (DPCA) frente a casos de violência sexual. Para tal, foi realizado um estudo qualitativo por meio da inserção ecológica e de entrevistas com profissionais. Foram realizadas 13 observações do cotidiano da delegacia e seis entrevistas com profissionais. Os dados provenientes dos registros das observações e das entrevistas foram analisados por meio da análise temática. A análise dos dados resultou em três temas: funcionamento, recursos e emoções. A DPCA estava em um processo de transição devido à aprovação da Lei 13.431/17, acarretando em suspensão de algumas atividades. A suspensão dessas atividades, aliada à falta de recursos materiais e humanos, resultou em não cumprimento do papel protetivo e de promotor de desenvolvimento da DPCA. Embora engajados, os profissionais relataram dificuldades, inclusive emocionais, em atender à demanda da violência sexual. Dada a recenticidade da aprovação da Lei, talvez esse seja o primeiro estudo a evidenciar o processo de transição que um serviço enfrenta para adequar-se a ela.
\end{abstract}

Palavras-chave: delitos sexuais, criança, adolescente, polícia.

\section{Proceedings of the Police Department for the Protection of Children and}

\section{Adolescents in Cases of Sexual Violence}

\begin{abstract}
Sexual violence against children and adolescents is a serious problem in Brazil. Strategies need to be planned aiming prevention and care of the victims. The present study aims to understand the actions taken by a police station to protect children and adolescents (DPCA, Portuguese acronym) in cases of sexual violence. A qualitative study was carried out, adopting the ecological insertion methodology and interviews. Thirteen observations of the
\end{abstract}


daily life of the police station and six interviews with practitioners were carried out. Thematic analysis was adopted to analyze data from the observations and interviews, resulting in three themes: functioning, resources and emotions. The DPCA was in a process of transition due to the approval of Law 13.431/17, resulting in suspension of some activities. The suspension of these activities, coupled with the lack of material and human resources, resulted in noncompliance with the roles of the DPCA. Although engaged, professionals reported difficulties, including emotional difficulties, in meeting the demand for sexual violence. Given the recent approval of Law, perhaps this is the first study to evidence the process of transition that a service faces to suit it.

Keywords: sexual offenses, child, adolescent, police.

\title{
Actuación de la Comisaría de Protección al Niño y al Adolescente en Casos
}

\author{
de Violencia Sexual
}

\section{RESUMEN}

La violencia sexual contra niños y adolescentes es un grave problema en el país. Las estrategias deben planificarse para la prevención y cuidado de las víctimas. Se ha objetivado comprender las acciones de una Comisaría de Protección al Niño y al Adolescente (DPCA, sigla en portugués) frente a casos de violencia sexual. Se realizó un estudio cualitativo por medio de la inserción ecológica y de entrevistas con profesionales. Se realizaron trece observaciones del cotidiano de la comisaría y seis entrevistas con profesionales. Los datos fueron analizados por medio del análisis temático. Se han identificado tres temas: funcionamiento, recursos y emociones. La DPCA estaba en un proceso de transición debido a la aprobación de la Ley 13.431/17, conllevando la suspensión de algunas actividades. La suspensión de esas actividades, asociada a la falta de recursos materiales y humanos, resultó en el no cumplimiento del papel protector y de promotor de desarrollo de la DPCA. Aunque comprometidos, los profesionales relataron dificultades, incluso emocionales, de atender a la demanda de la violencia sexual. Dada el carácter reciente de la aprobación de la Ley, tal vez ese sea el primer estudio que demuestre el proceso de transición que un servicio enfrenta para adecuarse a ella.

Palabras clave: delitos sexuales, niño, adolescente, policía.

A violência sexual contra crianças e adolescentes é um fenômeno complexo. Esse tipo de violência consiste em atos sexuais, bem como tentativas para conseguir manter relações ou investidas indesejadas realizadas por qualquer pessoa (Ministério da Saúde, 2002). Como possíveis consequências da violência sexual podem ser os danos primários (e.g., alterações nas funções emocionais e cognitivas), causados pela própria violência sexual, e os danos 
secundários, que são as intervenções inadequadas realizadas por profissionais que prestam atendimento às vítimas (Furniss, 1993).

Diante das consequências geradas pela violência sexual, houve necessidade de criar mecanismos legais de proteção a crianças e adolescentes. Com o intuito de garantir essa proteção, foi criado o Estatuto da Criança e Adolescente (ECA) - Lei n. 8.069 (1990) e, em 04 de abril de 2017, foi sancionada a Lei n. 13.431 (2017), que altera o ECA. Essa nova lei dispõe sobre o sistema de garantia de direitos da criança e do adolescente vítimas ou testemunhas de violência, visando a integração das políticas de atendimento (i.e., assistência e proteção qualificadas). Os órgãos que estão vinculados ao trabalho de proteção às vítimas são: sistema de justiça, segurança pública, assistência social, educação e saúde (art.14).

Estudos sobre violência sexual contra crianças e adolescentes são necessários para o seu melhor entendimento, para a proposição de estratégias de prevenção e para o oferecimento de atendimentos mais efetivos (Martins, 2017). Nessa perspectiva, a rede de proteção deve estar preparada para dar suporte às vítimas, evitando danos secundários. Tais danos podem ocorrer pela forma de escolha terapêutica e a não intervenção, estigmatização social, quando existem conflitos entre o sistema legal, as necessidades psicológicas e de proteção das vítimas (Furniss, 1993). Com o intuito de evitar os danos secundários, os serviços devem trabalhar de forma horizontal e com o objetivo de estabelecer o resgate dos direitos e a proteção das crianças e dos adolescentes (Costa, Xavier, \& Santos, 2011).

A rede de proteção às crianças e aos adolescentes vítimas de violência é constituída por vários serviços, que devem trabalhar de forma articulada, com intervenções definidas, visando um atendimento qualificado. Cada serviço prestado pela rede tem um papel específico visando a proteção das vítimas. O Conselho Tutelar (CT) normalmente é o primeiro que tem conhecimento dos casos, devendo fazer encaminhamentos necessários a outros serviços, tais como a notificação para a Delegacias de Proteção à Criança e ao Adolescente (DPCA). Assim, será iniciada a investigação e, se constatada a violação dos direitos da criança ou do adolescente, será realizado encaminhamento ao Ministério Público (Hohendorff, Habigzang, \& Koller, 2014). As delegacias de polícia fazem parte da secretaria da segurança pública. Suas atribuições estão determinadas pela Lei no 14.733 n. (2015) e objetivam a preservação das garantias dos cidadãos e a proteção à vida.

A polícia civil é uma instituição vinculada à rede de proteção. Suas competências estão descritas na Lei n. 10.994 (1997). São exemplos de algumas das suas atribuições: apurar infrações penais, determinar a realização de exames periciais, zelar pela ordem, estabelecendo para isso medidas de proteção ao indivíduo (art. 4). A Lei n. 10.994 (1997) também 
estabelece a organização das delegacias de polícia, sendo que as ocorrências envolvendo crianças e adolescentes são destinadas ao Departamento Estadual da Criança e Adolescente (DECA). A estrutura do DECA foi organizada pelo Decreto n. 41.049 (2001), sendo também criadas no decreto as DPCAs, que oferecem o mesmo serviço para as cidades do interior do estado.

Na Delegacia de Polícia, bem como nos Conselhos Tutelares, são realizadas notificações de violência sexual com maior frequência, conforme estudo realizado no município de Ijuí (RS). Tal estudo foi realizado por meio de entrevistas com oito profissionais da rede de proteção à criança. Evidenciou-se que os procedimentos adotados pela delegacia são os encaminhamentos para Secretaria Municipal da Saúde, para a realização de avaliação psicológica por profissionais da área de psicologia e para exame de corpo de delito no Departamento Médico Legal. Foram identificadas limitações na rede (e.g., realização de encaminhamentos), mas que há compreensão por parte dos profissionais sobre a importância do funcionamento da rede (Martins, 2017).

A percepção de agentes de proteção acerca dos serviços prestados foi abordada em um estudo realizado no município de Santa Maria (RS). Foram realizadas entrevistas com o delegado da DPCA, um promotor (Ministério Público) e três conselheiros tutelares. Os entrevistados relataram saber dos serviços que fazem parte da rede (e.g., Juizado da Infância e Juventude, Promotoria, DPCA), que se sentiam inseridos na rede do município e responsáveis pela proteção dos direitos das vítimas. Os profissionais indicaram que a rede deve funcionar por meio da comunicação entre todos os serviços, para que essa conexão resulte em serviços de melhor qualidade (Faraj, Siqueira, \& Arpini, 2016).

Em um estudo realizado em uma cidade da região metropolitana de Porto Alegre (RS), foram verificadas as medidas adotadas após a revelação da violência sexual e como a rede contribuiu para oferecer suporte às vítimas. Participaram 40 meninas, com idades entre nove e 16 anos. Identificou-se que 32,5\% das revelações não foram notificadas aos serviços de proteção, em $10 \%$ dos casos as famílias não realizaram nenhuma conduta protetiva após revelação; $35 \%$ das vítimas foram acolhidas em instituições, e 20\% dos agressores foram responsabilizados criminalmente, sendo que não houve especificação do tipo de responsabilização. Após as notificações, a rede adotou como medida de proteção o encaminhamento para atendimento psicológico. Constatou-se, por meio dos resultados, que a rede de proteção não estava contribuindo para possibilitar um desenvolvimento saudável das vítimas devido a fatores como falta de comunicação, de planejamento coordenado entre os 
serviços e falta de encaminhamentos para outros atendimentos (Habigzang, Ramos, \& Koller, 2011).

Embora existam estudos científicos sobre a atuação de profissionais nos casos de violência sexual contra crianças e adolescentes, tais estudos não têm como foco específico o funcionamento das DPCAs. Os estudos encontrados são referentes à realização dos encaminhamentos nas investigações de crimes relacionados a violência sexual contra crianças (Martins, 2017), compreensão da rede de proteção em geral (Faraj et al., 2016) e análise das medidas adotadas pela rede de apoio de crianças e adolescentes após a revelação (Habigzang et al., 2011). Esses estudos costumam recorrer à participação de profissionais, com utilização de entrevistas (Faraj et al., 2016; Martins, 2017), sendo apenas um realizado com vítimas (Habigzang et al., 2011). Percebe-se, então, a carência de estudos sobre a atuação das DPCAs nos casos de violência sexual, principalmente com a utilização de métodos de pesquisa que permitam o estudo no contexto em que os fenômenos ocorrem.

A inserção ecológica é um método de pesquisa baseado da Teoria Bioecológica do Desenvolvimento Humano (TBDH), de Urie Bronfenbrenner. A TBDH indica que o desenvolvimento humano se dá por meio das interações das pessoas em desenvolvimento e os ambientes em que estão inseridas (Bronfenbrenner, 1996). Assim, é necessário que as interações que possam ocorrer entre vítimas, e os serviços possibilitem o desenvolvimento saudável de crianças e adolescentes, assim como estes consigam influenciar tal ambiente.

A TBDH também indica como se dão as interações das pessoas com os seus contextos. Para tal, o modelo Processo-Pessoa-Contexto-Tempo (PPCT) foi proposto. O processo consiste nas interações recíprocas entre ambiente e a pessoa em desenvolvimento. A pessoa, com suas características biopsicológicas, influencia o ambiente imediato em que está inserida e sofre influência desse ambiente. Esses tipos de interações são conceituados como processos proximais, que são necessários ao desenvolvimento humano. Os processos proximais devem ter características específicas, existência de interações recíprocas entre a pessoa em desenvolvimento e demais indivíduos, objetos e símbolos presentes no contexto; as interações devem ter complexidade progressiva, regularidade, e serem mantidas por períodos estendidos de tempo. Na presença destas características, os processos proximais geram efeitos de competência, que consistem no desenvolvimento saudável do indivíduo por meio do controle e integração do seu comportamento. Do contrário, os efeitos de disfunção (i.e., dificuldade em manter o controle e integração do comportamento em diferentes situações) ocorrem quando o as interações da pessoa em desenvolvimento com o seu contexto se dão de forma 
desestruturada, inesperada, com excessiva estimulação e atividade (Bronfenbrenner \& Evans, 2000; Bronfenbrenner \& Morris, 1998).

Outro aspecto do modelo é o contexto onde os seres humanos se desenvolvem, sendo divididos em sistemas. $\mathrm{O}$ microssistema consiste nos ambientes nos quais ocorrem interações de forma imediata e com atividades do cotidiano (e.g., ambiente familiar). No mesossistema ocorrem interações das pessoas com dois ou mais microssistemas (e.g., escola e família). O exossistema se refere a um ambiente com o qual a pessoa em desenvolvimento não interage diretamente, mas sofre a sua influência (e.g., criança sofre influência do trabalho dos pais). Já o macrossistema diz respeito às ideologias e crenças da cultura em que todos sistemas estão inseridos (Bronfenbrenner, 1996). O último elemento do modelo é referente ao tempo em que essas interações ocorrem. É utilizado o termo cronossistema, que diz respeito ao desenvolvimento de processos proximais no decorrer de um processo histórico (Bronfenbrenner \& Morris, 1998).

A partir do modelo TBDH foi proposto o método inserção ecológica, que é utilizado em pesquisas em que o/a pesquisador/a deve estar inserido/a no ambiente ecológico que pretende investigar. $\mathrm{O}$ pesquisador/a deve tornar-se parte do ambiente, devendo estar envolvido/a em atividades por um período de tempo, permitindo que, por meio de suas experiências vividas no local, conheça os contextos, as pessoas e os padrões de interações que ocorrem nesse ambiente (Cecconello \& Koller, 2003).

Diante do exposto, o objetivo desse estudo foi o de compreender as ações de uma DPCA diante de casos de violência sexual contra crianças e adolescentes. Além disso, buscou-se verificar se o ambiente desta Delegacia era facilitador do desenvolvimento adequado de crianças e adolescentes vítimas de violência sexual à luz da TBDH.

\section{Método}

Realizou-se uma pesquisa qualitativa, baseada nos procedimentos da inserção ecológica (Cecconello \& Koller, 2003) em uma DPCA. A inserção ecológica constitui um método de pesquisa baseado na TBDH (Bronfenbrenner, 1996).

\section{Participantes}

Os participantes foram profissionais que atuavam na DPCA de um município do Norte do estado do Rio Grande do Sul, com idades entre 32 e 65 anos. No local existiam 10 
profissionais quando a pesquisa foi realizada. Foram realizadas conversas com todos os profissionais e entrevistas com seis profissionais (três escrivãs, uma inspetora, um delegado e um comissário chefe de investigação). Dois profissionais possuíam pós-graduação e quatro possuíam ensino superior completo, sendo que quatro dos entrevistados possuíam curso específico para atendimento de casos de violência sexual. Os demais profissionais com os quais não foram realizadas entrevistas foram duas estagiárias que trabalhavam como secretárias e dois inspetores. Não foram realizadas entrevistas com esses profissionais porque foi considerado que os conteúdos obtidos com a realização das demais entrevistas abarcavam o objetivo proposto neste estudo.

\section{Instrumentos}

Foram utilizadas fichas de dados sociodemográficos, que consiste em um instrumento utilizado para obtenção de informações sobre os participantes. Também foram utilizados diários de campo, em que as observações da pesquisadora foram registradas, em um diário de campo adaptado do modelo proposto por Coscioni (2017), dividido em três seções (i.e., sentimentos, percepções e observações de conversas informais). As entrevistas foram feitas segundo roteiro semiestruturado, utilizado para a compreensão de como era o funcionamento da delegacia a partir do relato dos profissionais. Foram utilizadas questões como "Me conta tudo sobre o funcionamento do serviço envolvendo ocorrências de violência sexual?", e “Após o recebimento das notificações de violência sexual, quais os procedimentos seguintes?”.

\section{Procedimentos éticos e de coleta de dados}

A pesquisa foi autorizada pelo responsável da DPCA e pelo Comitê de Ética. Os participantes assinaram o Termo de Consentimento Livre e Esclarecido (TCLE). Foi atribuído um número para cada participante, visando garantir o anonimato. Foram realizadas 13 observações, durante os meses de agosto e setembro de 2018, com duração média de uma hora e trinta minutos cada, perfazendo total de aproximadamente 19 horas e 30 minutos. As observações incluíram conversas informais com profissionais e o acompanhamento de 11 atendimentos de usuários, sendo finalizadas após dois meses devido ao fato de a DPCA estar em obras e não receber mais casos. As entrevistas foram realizadas nas salas dos profissionais, na própria DPCA e tiveram duração média de 22 minutos. 
Os atendimentos realizados foram de adultos, com o objetivo de coleta de depoimentos. Alguns usuários procuravam a DPCA para receber informação, dois usuários foram ao local para registrar ocorrência, sendo que o atendente informou que não estavam realizando tal procedimento e os encaminhou para a Delegacia de Polícia de Pronto Atendimento (DPPA), sem saber o motivo da ocorrência.

\section{Análise de dados}

As entrevistas foram transcritas na íntegra e os dados foram analisados conforme a proposta de análise temática de Braun e Clarke (2006). Inicialmente, foi realizada leitura do material transcrito. Em seguida, foi realizada a codificação dos assuntos relacionados ao objetivo da pesquisa, e com esta codificação, procedeu-se o agrupamento dos códigos (i.e., trechos) por semelhança, gerando os temas para análise. Os temas foram, então, revisados e os subtemas foram identificados. Por fim, foi confeccionada uma tabela com os temas, subtemas e exemplos de conteúdo. O software NVivo foi utilizado.

\section{Resultados}

Durante o processo de inserção ecológica na DPCA ocorreram processos proximais, em que aconteceram interações recíprocas entre pesquisadora, profissionais e também entre os profissionais. Houve trocas de informações sobre as demandas da delegacia, a reforma de uma sala para a realização do Depoimento Especial (DE), aquisição do conhecimento de como será realizado o depoimento e sobre a legislação. Especificamente em relação à implementação do DE, percebeu-se a influência de uma política pública (Lei n. 13.431, 2017) no microssistema observado. A adaptação de uma sala para a realização do DE alterou o funcionamento da DPCA estudada. Devido a isso, os resultados aqui apresentados refletem esse processo de transição, que pode ser entendido quando se leva em consideração características do tempo sociohistórico (cronossistema).

Desde o início do ano de 1990, principalmente com a promulgação do ECA (Lei n. 8069, 1990), a garantia de direitos de crianças e adolescentes vem sendo enfatizada. A primeira década do século XXI, no Brasil, vem sendo marcada por discussões acerca da efetividade das redes de proteção e de atendimento a crianças e adolescentes com seus direitos violados. Tem-se buscado maior integração dos serviços visando a redução de danos secundários. Sendo assim, a aprovação da Lei n. 13.431 (2017) reflete tal busca por 
aprimoramento da rede. A partir de sua recente aprovação, é esperado que haja um período de reformulações e adaptações nos serviços da rede conforme observado na DPCA estudada.

A partir da análise dos conteúdos advindos das entrevistas e das observações foram identificados três temas (Tabela 1).

Tabela 1

Temas, Subtemas e seus Exemplos a Partir das Entrevistas com Profissionais da DPCA e Observações

\begin{tabular}{|c|c|c|}
\hline Temas & Subtemas & Exemplos \\
\hline $\begin{array}{l}\mathrm{F} \\
\mathrm{U} \\
\mathrm{N} \\
\mathrm{C} \\
\mathrm{I} \\
\mathrm{O}\end{array}$ & Equipe & $\begin{array}{l}\text { "Ótima interação, em que há trocas de informaçðes sobre } \\
\text { procedimentos que estão trabalhando, conversas rápidas } \\
\text { sobre como está andamento das investigaçōes." (Obs) } \\
\text { "O pessoal é bastante integrado nessaárea, o pessoal se une } \\
\text { muito. O trabalho a gente vê bem padronizado, organizado, } \\
\text { bem profissional mesmo." (P6) }\end{array}$ \\
\hline \multirow[t]{4}{*}{$\begin{array}{l}\text { N } \\
\text { A } \\
\text { M } \\
\text { E } \\
\text { N } \\
\text { T } \\
\text { O }\end{array}$} & Notificaçōes & $\begin{array}{l}\text { "A delegacia recebe as denúncias por dois tipos } \\
\text { basicamente, o registro de ocorrências ou denúncias." (P2) } \\
\text { "Usuária chegou com alguns papéis de encaminhamento } \\
\text { para fazer ocorrência, a escrivã olhou e disse que ela } \\
\text { deveria se dirigir a DPPA para fazer o registro, pois ali no } \\
\text { momento não estavam realizando." (Obs) }\end{array}$ \\
\hline & Atendimento & $\begin{array}{l}\text { "Quando o delegado toma conhecimento, se já tem uma } \\
\text { suspeita da autoria do fato, o delegado instaura o } \\
\text { procedimento policial e encaminha para os cartórios } \\
\text { [escrivãs da DPCA] ou se o caso um pouco mais delicado, } \\
\text { que demanda uma certa investigação para confirmar uma } \\
\text { suspeita de autoria, ele manda para o pessoal da } \\
\text { investigação." (P2) }\end{array}$ \\
\hline & Transição & $\begin{array}{l}\text { "A escrivã explicou que devido à reforma de sua sala, ela } \\
\text { não poderia atender e que iria ligar para agendar outro } \\
\text { horário.(Obs); Agora a gente tá um certo período sem lidar } \\
\text { com as crianças aqui, que a gente tá adequando a delegacia } \\
\text { para essa nova lei" (P2) }\end{array}$ \\
\hline & Financeiro & $\begin{array}{l}\text { "Falta de material, falta de estrutura e isso é problema } \\
\text { econômico, e tudo que envolva treinamento, envolve } \\
\text { dinheiro, não adianta" (P1) } \\
\text { "Acho que deveria ter uma atenção maior da policia civil, } \\
\text { digamos de direção no caso, dá mais amparo, a gente vê } \\
\text { que é uma delegacia que menos ganha recurso, que é } \\
\text { desassistida em muitos casos". (P6) }\end{array}$ \\
\hline
\end{tabular}


Humanos

$\begin{array}{ll}\text { R } & \\ \text { E } & \\ \text { C } & \\ \text { U } & \text { Capacitação } \\ \text { R } & \\ \text { S } & \\ \text { O } & \\ \text { S } & \end{array}$

Suporte psicológico aos profissionais

Suporte às vítimas
"Até porque somos poucos, temos que fazer render." (P3); "Pela falta efetivo a gente sente muita dificuldade em desenvolver esse trabalho." (P4)

"Até o último curso de capacitação foi o mês passado lá no DECA, juntamente em convênio com o Tribunal de Justiça, nós tivemos dois dias de aula, sobre entrevista forense que engloba todo esse tipo de atendimento, de recebimento por parte da delegacia de crianças vítimas de violência, como a gente deve lidar com as crianças, conversar com as crianças e depois todo o encaminhamento à rede de proteção." (P2) "Mas falta bastante, mais ferramentas para nós, mais curso nessa área, até para ampliar nosso horizonte de investigação." (P6)

"Nós somos tudo, temos que ser tudo e nós não temos um suporte para isso, nós temos que ser isso." (P3); "Não tem, năo tem nenhum suporte." (P5)

"Dá bastante uma certa noção que falta uma atitude mais do estado, descaso, a própria vitima que fica mercê do abusador, a sensação de impunidade, tudo isso aí." (P6); "Teria que ter aqui dentro psicóloga, teria que ter um psicólogo, um assistente social, as duas para ter essa parte de acolhimento." (P6)

"Já aconteceu de duas ou três vezes chavear a porta da delegacia e ir chorando para casa, me abalar com questões assim. Até agora conversando contigo, você percebe que eu me abalo emocionalmente, então não é fácil" (P2); "Não posso te precisar quantos, mas foram vários, vários... às vezes eu acho que não vou dar conta de continuar trabalhando aqui." (P3)

Manejo Emocional "Mas a gente procura não levar, porque tu adoece, adoece e muito das coisas, dor de cabeça, dor de estômago, essas coisas para mim é comum... comum. O corpo adoece." (P3)

"Mas eu já sei lidar bem melhor, assim com casos que chocam. Separar as coisas, tentar manter o profissionalismo, mas isso não impede que tu não fique abalada com uma coisa que tu vê." (P5)

Nota. Obs: Observação. P: Profissional.

No primeiro tema constam conteúdos sobre o funcionamento da DPCA analisada. De forma geral, o funcionamento da DPCA ocorre com uma relevante integração da sua equipe, possibilitando dessa maneira a divisão das tarefas. Quando alguma notificação chegava à DPCA, de imediato ocorria instauração de inquérito e encaminhamento para um dos profissionais. O serviço era facilitado pelo fato de ser ter uma rotina planejada, e dessa maneira possibilitava um ambiente mais organizado. Esse tema possui cinco subtemas, sendo eles: equipe, notificação, atendimento, relacionamento com a rede e transição. 
Conteúdos acerca do vínculo existente entre os membros da equipe foram incluídos no subtema "equipe". Percebeu-se que os profissionais mantiveram grande integração, em que ocorriam constantes interações sobre os procedimentos e organização da rotina. Por exemplo, em uma das observações da pesquisadora, uma escrivã contou que estava irritada, pois sabia que uma vítima de violência sexual estava sendo ameaçada. Neste momento, alguns colegas (delegado, secretária) chegaram, ouviram-na e discutiram estratégias de solução do caso. Diante disso, é possível verificar a existência de processos proximais entre os membros da equipe, já que interações como a descrita anteriormente foram observadas diversas vezes.

No subtema "notificações", há conteúdos referentes às formas como chegavam as demandas de violência sexual. Foram citadas duas formas principais de recebimento: registros de ocorrências e notificações anônimas. Os registros das ocorrências eram realizados na DPPA, que geralmente são registradas por familiares das vítimas e pelo CT. As notificações são realizadas via telefone, e-mail e disque-denúncia. No terceiro subtema, "atendimentos", percebeu-se que sempre que alguma notificação era recebida, o delegado instaurava inquérito policial e distribuía para as escrivãs, que deviam dar prosseguimento ao inquérito. Quando não havia suspeita da autoria do crime, era instaurado inquérito e encaminhado para os agentes de investigação. Os profissionais relataram que os casos de VS sempre foram tratados como prioridade, sendo atendidos e solucionados primeiro. Referente aos atendimentos prestados pela delegacia, os profissionais consideraram os atendimentos bons, sendo o bemestar das vítimas o aspecto mais importante. Ao serem questionados como se avaliavam na execução das suas tarefas, os profissionais revelaram que se percebiam agindo com profissionalismo e sentiam-se preparados para prestar os atendimentos.

Conteúdos sobre a articulação entre a DPCA e os demais serviços foram incluídos no subtema "relacionamento com a rede". Os profissionais relataram que são realizados encaminhamentos aos serviços, tais como Conselho Tutelar, Fórum, Ministério Público e Departamento Médico Legal, todos do mesmo município onde estava localizada a DPCA. De acordo com eles, existia uma boa comunicação com os serviços da rede, sendo o mais contatado o CT, para acompanhar os casos, e o Ministério Público, para solicitação de prisão temporária ou preventiva do/a possível agressor/a. De acordo com o setor de investigação da DPCA (i.e., dois inspetores e um comissário), no entanto, costumavam ocorrer falhas na comunicação entre os serviços (e.g., Conselho Tutelar, Fórum, Ministério Público e Departamento Médico Legal) devido à diferenciação das linguagens e da não existência de um sistema normatizado, em que a forma de comunicação entre todos os serviços fosse padronizada. Os contatos entre a DPCA e os demais serviços da rede formam, portanto, um 
mesossistema, no qual relações entre diferentes microssistemas ocorriam. Percebe-se que as intervenções em nível de mesossistema estavam prejudicadas devido às falhas de comunicação, o que, possivelmente, acarretava em intervenções não planejadas de forma conjunta.

No subtema "transição" foram incluídas informações relacionadas à adaptação da DPCA à Lei n. 13.431 (2017). Essa transição remete a um período sócio histórico (i.e., macrotempo), no qual a DPCA estava sofrendo influência da aprovação da referida lei. A aprovação da lei pode ser considerada uma mudança no macrossistema que estava se refletindo no microssistema da DPCA, gerando alterações no atual funcionamento da DPCA (como não atendimento das crianças e adolescentes, realização de capacitações para atuação no Depoimento Especial).

Estavam ocorrendo capacitações dos profissionais para realização dos DEs e o ambiente sendo adaptado para a criação da sala de tais depoimentos. Os profissionais relataram que a nova lei estava limitando a oferta de serviços que eram realizados, tais como realização de depoimentos e encaminhamentos para um centro local de atendimento psicoterápico. Além disso, os profissionais indicaram que havia maior espera para a resolução dos casos, pois solicitavam a realização dos depoimentos para o fórum e aguardavam para finalizar os procedimentos.

Alguns profissionais mostraram estar confusos sobre a execução das suas atividades diante da aprovação da Lei n. 13.431 (2017). Ao explicar seu posicionamento acerca da maior exposição das vítimas aos agressores por conta da aprovação da Lei, percebeu-se certa confusão da profissional (P3) acerca da lei, pois ela afirmou que não poderiam mais interagir com a vítima. Outro profissional (P4) indicou que nos casos de violência sexual, o depoimento não será feito na DPCA, sendo realizado no fórum. Enquanto isso, as escrivãs da DPCA (P2, P5) relataram realização de cursos específicos para coleta do Depoimento Especial, indicando sua realização na DPCA.

As condições em que os profissionais executavam suas atividades foram incluídas no tema "recursos". Foi possível constatar a falta de recursos materiais e humanos, dificultando, dessa forma, um serviço mais efetivo. Os profissionais relataram dificuldades para o desenvolvimento de suas competências. Devido à grande demanda, acabavam por delimitar seus serviços aos urgentes (e.g., violência sexual de crianças e casos que necessitavam uma medida preventiva), sendo que, por vezes, achavam que não conseguiriam dar conta dos serviços. Por meio das observações, verificou-se que esse tema possui seis subtemas, sendo 
eles: financeiro, materiais, humanos, capacitação, suporte psicológico aos profissionais e suporte às vítimas.

Os relatos dos profissionais acerca de a DPCA ser a delegacia que costumava receber menos investimentos, sendo repassada pouca verba, foram incluídos no subtema "relacionamento com a rede". Durante as observações, foi possível constatar que o ambiente da DPCA era precário, com pouco espaço e necessitando de reformas. No subtema "materiais" foram incluídas informações sobre a falta de repasse de materiais (e.g., viaturas, materiais de informática). Foi observado que na DPCA havia materiais em mau estado de conservação (e.g., brinquedos, assoalho da sala de espera) e materiais antigos (e.g., computadores, mesas, cadeiras). No subtema "humanos", foram incluídas informações referentes à falta de recursos humanos. Como consequência, os profissionais sentiam-se sobrecarregados e as ocorrências deixaram de ser registradas no ano de 2017, pelo fato de não haver profissionais suficientes para essa demanda, sendo registradas na DPPA.

O conteúdo do subtema "capacitação" evidenciou a existência de investimentos na capacitação de profissionais escrivãs que trabalhavam nos cartórios. Tais cursos eram oferecidos pelo DECA e pelo Tribunal de Justiça. Além deles, foram citados cursos oferecidos pela Secretaria Nacional da Segurança Pública, pertencente ao Ministério da Justiça. De acordo com os profissionais, os últimos cursos foram realizados por duas escrivãs para atuação no DE. Em contrapartida, os profissionais que trabalhavam no setor de investigação relataram que não recebiam capacitação, pois os cursos não eram destinados à área de investigação, acarretando em falta de subsídios para um serviço mais qualificado. No subtema "suporte psicológico aos profissionais" foram incluídos conteúdos relacionados à falta que os profissionais percebiam de um serviço que lhes oferecesse suporte psicológico diante dos temas com os quais costumavam trabalhar. De acordo com eles, apenas na capital do estado era oferecido tal suporte aos profissionais.

O subtema "suporte às vítimas" inclui conteúdos relacionados à falta de suporte às vítimas atendidas. Os entrevistados relataram que não havia profissionais da Psicologia e do Serviço Social que pudessem oferecer suporte (e.g.: acolhimento) às crianças e aos adolescentes na DPCA. Além disso, os entrevistados consideraram a falta de suporte às vítimas no que diz respeito ao contato com os possíveis agressores. De acordo com os entrevistados, havia uma "falta de atitude do estado, em que as vítimas ficam à mercê do agressor" (P6).

No último tema constam conteúdos referentes às emoções experienciadas pelos profissionais durante suas atuações em casos de violência sexual. Foi possível constatar que 
os profissionais se mobilizam emocionalmente, revelando sentir, em alguns momentos, irritação, pressão por acharem que não iriam dar conta das suas atribuições, pensar muito em determinados casos, sentir que o corpo adoecia pela complexidade dos casos. Esse tema possui um subtema, denominado "manejo emocional". Nesse subtema foram incluídas informações acerca das estratégias pessoais que cada profissional relatou utilizar diante da mobilização emocional provocada pelos casos atendidos. As estratégias citadas foram as tentativas de não se envolverem emocionalmente, buscando o profissionalismo; manter a calma e o autocontrole, utilizando, principalmente, o vínculo com a equipe como suporte. Pode-se entender, portanto, a existência de processos proximais entre os profissionais, podendo gerar, dessa forma, efeitos de competência. Percebeu-se, durante as observações e na análise das entrevistas, que as interações entre os profissionais se configuravam como apoio emocional diante da demanda de trabalho.

\section{Discussão}

O objetivo deste estudo foi compreender as ações de uma DPCA frente aos casos de violência sexual. Para tal, a pesquisadora se inseriu na DPCA, realizando observações do seu funcionamento, bem como realizou entrevistas com profissionais.

Tomados em conjunto, os temas provenientes da análise de dados indicam que o funcionamento da delegacia se dá por constante integração da sua equipe, ocorrendo interações dos profissionais sobre os procedimentos a serem realizados e por quem serão executados. Estas interações estabelecidas possibilitam uma organização de todo o seu funcionamento, sendo oferecidos serviços mais adequados aos usuários e que ocorram processos proximais dos envolvidos. Os processos proximais ocorrem quando há um padrão de interação, em que são contínuas as trocas de informações entre pessoas em um determinado contexto (Cecconello \& Koller, 2003).

Foi possível perceber que as interações entre os profissionais eram frequentes. Tais interações objetivavam discutir casos, planejar procedimentos e, também, realizar conversas informais sobre o cotidiano pessoal de cada profissional. Também auxiliavam os profissionais, inclusive, no manejo de suas emoções em relação aos casos de violência sexual atendidos. Assim, conclui-se que essas interações podem ser consideradas processos proximais com efeitos potencialmente de competência. Os efeitos de competência dizem respeito ao controle e integração de comportamento (Bronfenbrenner, 1999). A interação com compartilhamento de suas emoções acerca dos casos parece ter auxiliado os profissionais a 
manejá-las. Nesses momentos de interação ocorria alívio da carga emocional ao estabelecerem trocas de experiência e apoio mútuo. Os profissionais buscavam o controle de suas emoções de forma a diminuir a sua interferência na atuação com os usuários, uma vez que foi mencionado agirem com "profissionalismo" (P1).

Durante a realização deste estudo, a DPCA estava passando por um período de transição e adaptação à Lei n. 13.431 (2017), em que foi possível verificar alterações estruturais e dos profissionais que estavam inseridos naquele contexto. Nessa perspectiva, pode-se analisar os fatores do modelo PPCT, em que foram visíveis as mudanças que estavam ocorrendo. Muitos dos conteúdos das interações eram voltadas ao novo modelo de depoimento e à reforma dos ambientes destinados para esse fim. No entanto, esse período de transição acabou limitando as interações entre a DPCA e seu principal público de atendimento - crianças e adolescentes. Tal limitação já existia há cerca de um ano, devido à falta de agentes para realização dos procedimentos. Diante disso, percebe-se uma descontinuidade nas interações, o que pode refletir em efeitos de disfunção aos usuários que precisaram recorrer a outros serviços. Sabe-se que interações que ocorrem de forma desestruturada, inesperada, com excessiva estimulação e atividade podem gerar efeitos de disfunção (Bronfenbrenner \& Evans, 2000; Bronfenbrenner \& Morris, 1998).

Outro fator que se percebeu foi a confusão sobre a nova lei e sua aplicação nas atividades executadas pela DPCA. Foi relatado por um profissional (P3) que não poderia ocorrer contato com a vítima. Também houve relato de um profissional (P4) de que não seriam realizados os depoimentos dos casos de violência sexual na DPCA, e sim no fórum. De acordo com a Lei n. 13.431 (2017), "Depoimento especial é o procedimento de oitiva de criança ou adolescente vítima ou testemunha de violência perante autoridade policial ou judiciária” (Art. $8^{\circ}$ ). É necessário, portanto, que além da aprovação da lei, sejam promovidas ações de esclarecimento sobre seus procedimentos.

Em relação ao suposto papel protetivo da DPCA, foram verificados aspectos desfavoráveis ao cumprimento desse papel e à contribuição ao desenvolvimento adequado de seus usuários. Diferentes fatores parecem contribuir para esse panorama. A falta de investimentos na DPCA foi percebida por meio da escassez de recursos materiais (e.g., viatura, móveis, material de informática) e humanos (e.g., maior número de agentes, capacitações), podendo prejudicar a qualidade dos atendimentos e acarretar dificuldades emocionais aos profissionais. Um profissional mencionou a "falta de atenção do estado para esse tipo de serviço" (P2). Sendo assim, conclui-se que a estrutura oferecida aos usuários, bem como a organização da DPCA em relação à rede, não eram suficientemente adequadas 
para que o atendimento oferecido contribuísse positivamente ao desenvolvimento dos seus usuários. Tal panorama pode estar restrito ao período de realização da pesquisa, no qual a DPCA estava em processo de transição, buscando adaptar-se às diretrizes da Lei n. 13.431 (2017). A falta de estruturas adequadas e a presença de ambientes desorganizados por falta de investimentos podem influenciar o desenvolvimento das pessoas, repercutindo em efeitos de disfunção (Bronfenbrenner, 1999).

Os profissionais relataram a importância de um suporte psicológico para o enfrentamento das questões emocionais vivenciadas na prestação dos seus serviços na DPCA, bem como para melhor acolhimento dos usuários. Estudo prévio já evidenciou a importância da presença de psicólogos em DPCAs, seja para oferecer suporte psicológico aos profissionais, seja para os usuários. Considera-se que o suporte psicológico aos profissionais pode evitar adoecimentos e falta de comprometimento com o serviço prestado (Alcoforado, 2018). É importante oferecer um atendimento que possa contar com uma equipe multiprofissional, com o objetivo de promover intervenções qualificadas que possibilitem todo o suporte necessário para as vítimas (Garcia, Macieira, \& Oliveira, 2017).

No que diz respeito ao relacionamento com a rede, os profissionais mencionaram o apoio de outros serviços. Sempre que necessários, eram realizados encaminhamentos e contatos entre eles. No entanto, foi constatada a fragilidade na articulação da rede. Profissionais do setor de investigação relataram dificuldade de comunicação relacionadas às diferenças nas linguagens utilizadas pelos serviços. Em estudo recente, a comunicação entre os serviços foi indicada pelos profissionais entrevistados como um dos principais aspectos necessários para a real efetivação de um trabalho em rede (Farajet al., 2016). Diante disso, é necessário que todos os profissionais tenham clareza sobre a atuação dos serviços onde estão inseridos, bem como da atuação dos serviços que fazem parte da rede. Devem buscar conhecimento para que possam dialogar com profissionais de diferentes áreas e serviços, potencializando a comunicação efetiva, planejamento conjunto de intervenções para o bemestar dos usuários (Hohendorff et al., 2014).

Os aspectos positivos mencionados pelos profissionais merecem destaque. A frequência de capacitação para alguns profissionais, bem como o interesse demonstrado para atualizações, refletem o comprometimento desses profissionais em disponibilizar intervenções adequadas. Sendo assim, é possível perceber a disposição dos profissionais em se engajar em processos proximais (como cursos, capacitações) que promovam seu desenvolvimento. De acordo com o modelo PPCT, há três principais características da pessoa em desenvolvimento que influenciam sua participação em processos proximais (i.e., disposições, recursos 
bioecológicos e demanda). As disposições podem ser generativas (e.g., curiosidade, engajamento em atividades) ou inibidoras (e.g., impulsividade, desatenção), e atuam facilitando ou não a ocorrência de processos proximais (Bronfenbrenner \& Morris, 1998).

Diante da complexidade dos casos de violência sexual contra crianças e adolescentes, a capacitação constante dos profissionais é necessária (Hohendorff et al., 2014). Para que ela ocorra, é necessário não somente a disposição dos profissionais, mas que os gestores destinem recursos para a realização de capacitações periódicas. A formação e as capacitações periódicas facilitam a atuação profissional em rede. Profissionais com aprofundamento teórico-prático, "sobretudo na área dos direitos da criança e do adolescente, serão capazes de romper com o isolamento e compartilhar saberes, discutir situações, tomar decisões em conjunto, ou seja, sair das 'caixinhas'" (Faraj et al., 2016, p. 738).

\section{Considerações Finais}

Por meio desse estudo foi possível perceber que o funcionamento da DPCA parece estar intimamente relacionado ao momento sócio-histórico vivido. O microssistema DPCA estava passando por um processo de mudanças e adaptação, resultante de influências provenientes do macrossistema. Esse acontecimento de alteração de uma política pública fez com que a delegacia tivesse que se preparar para o cumprimento da Lei n. 13.431 (2017). Durante a realização do estudo, percebeu-se que houve dificuldades de entendimento de como seria realizado de fato o DE, visto terem ocorrido divergências entre as informações prestadas.

Visando adequar-se à realização do DE, a DPCA estava passando por reformas, o que acarretou a suspensão dos atendimentos de crianças e adolescentes. Portanto, durante todo o processo de inserção da pesquisadora na DPCA, não foi possível observar atendimentos às crianças e aos adolescentes. Tal fato pode ser indicado como uma limitação do estudo relacionada ao momento de transição que a DPCA estava vivenciando. Aliado a isso, o tempo de realização do estudo, a duração das observações, bem como das entrevistas, foram relativamente breves. Embora não tenha sido encontrado indicativo metodológico de tempo mínimo de inserção no contexto analisado, inserções por períodos de tempo mais longos permitiriam a apreensão de mais informações. Assim, sugere-se que sejam planejados períodos de inserção ecológica mais prolongados em estudos futuros. Especificamente em relação ao estudo realizado, considera-se que um novo período de inserção ecológica, quando da retomada dos atendimentos às crianças e aos adolescentes, poderia aumentar a 
compreensão sobre o período de transição vivenciado pela DPCA. A inserção da pesquisadora na DPCA justamente durante um período de transição permitiu analisá-lo.

Por conta dessa transição, pode-se supor que a DPCA investigada não estava contribuindo para o desenvolvimento de seus usuários. Considera-se que a DPCA não estava cumprindo totalmente seu papel protetivo e de contribuição ao desenvolvimento pleno das crianças e adolescentes devido, principalmente, à interrupção dos atendimentos. No entanto, o engajamento dos profissionais ficou evidente. Os profissionais da DPCA buscavam constantemente disponibilizar intervenções adequadas. Além disso, esses profissionais indicaram aspectos necessários para que a DPCA cumpra com seu papel protetivo e de promoção do desenvolvimento humano. $\mathrm{O}$ aumento no número de profissionais, a realização de mais cursos de capacitação e oferecimento de suporte psicológico tanto para equipe quanto para os usuários foram citados como necessários para a melhor atuação da DPCA. Tudo isso depende de mais investimentos dos gestores do serviço, que atualmente passa por uma crise econômica severa, sofrendo corte de verbas em todas as modalidades dos serviços públicos.

A atual crise econômica do estado (macrossistema), com déficit no ano de 2018 estimado em $\mathrm{R} \$ 6,9$ bilhões, causa ainda mais prejuízos aos serviços prestados pela segurança pública. O agravamento da crise econômica pode ser explicado por vários fatores, como o aumento das despesas com pessoal e a falha das medidas estabelecidas para diminuir os gastos. Neste sentido, ações para amenizar a situação da falta de agentes foram realizadas pelo governo estadual. Cita-se como exemplo a realocação de funcionários da extinta Fundação de Economia e Estatística (FEE) na polícia civil, conforme consta no Diário Oficial do Estado n ${ }^{\circ}$ 128, do dia 06 de julho de 2018. Embora tal iniciativa possa solucionar quantitativamente a escassez de agentes, é necessário atentar para o fato de que tais agentes precisam de capacitação específica para atuação em delegacias como as DPCAs.

Por fim, esse estudo evidencia como a aprovação da Lei n. 13.431 (2017) estava repercutindo o serviço da rede. Dado o caráter recente da aprovação dessa Lei, este talvez esse seja o primeiro estudo a evidenciar o processo de transição que o serviço enfrenta. Estudos futuros podem verificar como o serviço se adaptou às diretrizes da lei, bem como as estratégias utilizadas para sua efetivação. 


\section{Referências}

Alcoforado, E. S. (2016). Abuso sexual: Formação profissional, condições de enfrentamento da proteção social especial e o adoecimento do profissional que atua no atendimento às vítimas. Temporalis, 18(35), 372-381. doi:10.22422/temporalis.2018v18n35p372381

Brasil. (1990, Julho 13). Lei $n^{o}$ 8.069. Dispõe sobre o Estatuto da Criança e do Adolescente e dá outras providências. Brasília, DF: Presidência da República. Recuperado de http://www.planalto.gov.br/ccivil_03/leis/L8069.htm

Brasil. (1997, Agosto 18). Lei $n^{o}$ 10.994. Estabelece organização básica da Polícia Civil, dispõe sobre sua regulamentação e dá outras providências. Rio Grande do Sul: Assembléia Legislativa. Recuperado de http://www.al.rs.gov.br/FileRepository/repLegisComp/Lei\%20n\%C2\%BA\%2010.994. pdf

Brasil. (2001, Setembro 17). Decreto $n^{o}$ 41.049. Dispõe sobre estrutura orgânica do Departamento Estadual da Criança e do Adolescente (DECA). Rio Grande do Sul: Assembléia Legislativa. Recuperado de http://www.al.rs.gov.br/legislativo/Legisla\%C3\%A7\%C3\%A3oEstadual.aspx

Brasil. Ministério da Saúde (2002). Violência intrafamiliar: Caderno de atenção básica. Brasília, DF: Ministério da Saúde. Recuperado de http://bvsms.saude.gov.br/bvs/publicacoes/cd05_19.pdf

Brasil. (2015, Setembro 15). Lei $n^{o}$ 14.733. Dispõe sobre a estrutura administrativa e diretrizes do Poder Executivo do Estado do Rio Grande do Sul e dá outras providências. Rio Grande do Sul: Assembléia Legislativa. Recuperado de http://www.al.rs.gov.br/filerepository/repLegis/arquivos/LEI\%2014.733.pdf

Brasil. (2017, Abril 4). Lei $n^{o}$ 13.431. Estabelece o Sistema de Garantia de Direitos da Criança e do Adolescente vítima ou testemunha de violência e altera a Lei no 8.069, de 13 de julho de 1990. Brasília, DF: Presidência da República. Recuperado de http://www.planalto.gov.br/ccivil_03/_ato2015-2018/2017/lei/L13431.htm

Braun, V., \& Clarke, V. (2006). Using thematic analysis in psychology. Qualitative Research in Psychology, 3(2), 77-101. doi:10.1191/1478088706qp063oa

Bronfenbrenner, U. (1996). A ecologia do desenvolvimento humano: Experimentos naturais e planejados (M. A. V. Veronese, Trad.). Porto Alegre: Artes Médicas. 
Bronfenbrenner, U., \& Morris, P. A. (1998). The ecology of developmental processes. In W. Damon (Org.), Handbook of child psychology (pp. 993-1027). New York: Wiley \& Sons.

Bronfenbrenner, U. (1999). Environments in developmental perspective: Theoretical and operational models. In B. L. Friedman \& T. D. Wachs (Orgs.), Conceptualization and assessment of environment across the life span (pp 3-28). Washington, DC: American Psychological Association.

Bronfenbrenner, U., \& Evans, G. W. (2000). Developmental science in the 21st century: Emerging questions, theoretical models, research designs and empirical findings. Social Development, 9(1), 115-125. doi:10.1111/1467-9507.00114

Cecconello, A. M., \& Koller, S. H. (2003). Inserção ecológica na comunidade: Uma proposta metodológica para o estudo de famílias em situação de risco. Psicologia: Reflexão e Crítica, 16(3), 515-524. doi:10.1590/S0102-79722003000300010

Coscioni, V. (2017). Systematization of recording in field diary: A case of a research in brazilian juvenile detention centers. In D. D. Dell'Aglio \& S. H. Koller (Eds.), Vulnerable Children and Youth in Brazil: Innovative approaches from the Psychology of Social Development (pp. 261-273). New York: Springer.

Costa, L. F., Xavier, A., \& Santos, V. A. (2011). As medidas protetivas na perspectiva de famílias em situação de violência sexual. Psico, 42(1), 77-86. Recuperado de https:://revistaseletronicas.pucrs.br/ojs/index.php/revistapsico/article/view/6463/6303

Faraj, S. P., Siqueira, A. C., \& Arpini, D. M. (2016). Rede de proteção: O olhar de profissionais do sistema de garantia de direitos. Temas em Psicologia, 24(2), 727-741. doi:10.9788/TP2016.2-18

Furniss, T. (1993). Abuso sexual da criança e adolescente: Uma abordagem multidisciplinar (M. V. A. Veronese, Trad.). Porto Alegre: Artes Médicas.

Garcia, P. A., Macieira, A. P., \& Oliveira, D. E. S. D. (2017). O trabalho da equipe multiprofissional com crianças e adolescentes vítimas de violência sexual atendidas na unidade hospitalar. Revista do Laboratório de Estudos da Violência da UNESP/Marília, 20(20), 29-56. Recuperado de http://www2.marilia.unesp.br/revistas/index.php/levs/article/view/7515

Habigzang, L. F., Ramos, M. da S., \& Koller, S. H. (2011). A revelação de abuso sexual: As medidas adotadas pela rede de apoio. Psicologia: Teoria e Pesquisa, 27(4), 467-473. doi:10.1590/S0102-37722011000400010 
Hohendorff, J. V., Habigzang, L. F., \& Koller, S. H. (2014). Violência sexual contra meninos: Teoria e intervenção. Curitiba: Juruá.

Martins, A. (2017). Violência sexual contra crianças: A proteção integral e a materialidade dos crimes sexual (Dissertação de Mestrado). Pontifícia Universidade Católica do Rio Grande do Sul, Porto Alegre, RS, Brasil. Recuperado de http://repositorio.pucrs.br/dspace/bitstream/10923/11093/1/000488034-

Texto\%2bCompleto-0.pdf

Rio Grande do Sul. (2018). Diário Oficial do Estado. Recuperado de http://www.pge.rs.gov.br/upload/arquivos/201807/06085212-doe-ultimo06072018.pdf

\section{Endereço para correspondência}

\section{Fernanda Corrêa}

Rua Senador Pinheiro, 304, Passo Fundo - RS, Brasil. CEP 99070-220

Endereço eletrônico: fernanda.correapsi@gmail.com

\section{Jean Von Hohendorff}

Rua Senador Pinheiro, 304, Passo Fundo - RS, Brasil. CEP 99070-220

Endereço eletrônico: jhohendorff@gmail.com

Recebido em: 28/03/2019

Reformulado em: 04/02/2019

Aceito em: 11/11/2019

\section{Notas}

* Psicóloga formada pela Faculdade Meridional de Passo Fundo - IMED, Passo Fundo, Rio Grande do Sul, Brasil.

** Professor no Programa de Pós-Graduação em Psicologia Stricto Sensu da Faculdade Meridional de Passo Fundo - IMED, Passo Fundo, Rio Grande do Sul, Brasil.

Financiamento: Fundação de Amparo à Pesquisa do Rio Grande do Sul (FAPERGS) - Edital 01/2017 - ARD e Fundação IMED

Este artigo de revista Estudos e Pesquisas em Psicologia é licenciado sob uma Licença Creative Commons Atribuição-Não Comercial 3.0 Não Adaptada. 